\title{
Re-imagining the Past and Mastering the Present: The Power of Analogical Arguments in American Presidents' and Celebrities'
}

\author{
Hana Riani \\ Faculty of Arts and Humanities, Department of English, Sousse, Tunisia \\ hannarayani@outlook.fr
}

DOI: http://doi.org/ 10.36892/ijlls.v4i1.793

\begin{tabular}{|c|c|}
\hline $\begin{array}{l}\text { Received: } \\
\text { 25/12/2021 }\end{array}$ & $\begin{array}{c}\text { Abstract } \\
\text { Inspecting the genealogy of American sta }\end{array}$ \\
\hline & $\begin{array}{l}\text { historical knowledge grasped out of past experiences has been framed as a } \\
\text { social reality that has been justified with consistency and uncompromising } \\
\text { conviction by different political actors to contain global threats. The present } \\
\text { article studies how analogical analysis is engaged in linking various texts of }\end{array}$ \\
\hline $\begin{array}{l}\text { Keywords: } \\
\text { Analogical Analysis, } \\
\text { Politico- } \\
\text { humanitarian } \\
\text { Discourse, } \\
\text { Celebrities, } \\
\text { Presidents, Ideology, } \\
\text { CDA }\end{array}$ & $\begin{array}{l}\text { different genres, though displayed by different actors at different points in } \\
\text { history, embed common themes and ideologies. In this regard, this study is an } \\
\text { attempt to uncover the analogical construct underlying US presidents' (George } \\
\text { W.H. Bush and George W. Bush) and celebrities' (Ben Affleck and George } \\
\text { Clooney) discourses by investigating the extent to which their analogical } \\
\text { reasoning contributes to the construction of common ideologies. To unpack this } \\
\text { argument, the paper also scrutinizes the linguistic parameters of analogies by } \\
\text { delineating the linguistic devices aimed at reinforcing the tenor of the analogy. } \\
\text { To study the implications of the analogical arguments communicated in the } \\
\text { language of these political actors, the research adopts a theoretical scheme } \\
\text { combining Fairclough's Critical Discourse Analysis and Analogy. The findings } \\
\text { bring out that their analogical reasoning, reinforced by linguistic toolkits, } \\
\text { draws on the retreat strategy to legitimize US foreign policy in the Third-World. }\end{array}$ \\
\hline
\end{tabular}

\section{INTRODUCTION}

There has been a growing interest from political scientists and historians in analyzing the extent to which lessons from the past, veiled in the shape of historical analogies, forge the political choices of policymakers. Since the old days of Herodotus, Niccolò Machiavelli, Edward Gibbon, and many others, the tradition of reviving history to demystify lessons of leadership guided many politicians throughout ages. Paralleling such a tradition, the American political discourse espouses a coherent worldview where past events work as a cognitive archive based on which politicians' future political goals are measured. What plays a crucial role in this process is language since every political action is influenced by the use of language (Hague, Harrop, and MCcormick, 1998). This use, in turn, creates effects of power and legitimacy which are recognized as being intrinsically linked to politics. In fact, the power of successful politicians' language depends on its ability to persuade and for the sake of persuasion, among other rhetorical devices; highly conventionalized analogies are leaned on to maintain the complex nexus of history, and power. The renegotiation of the past as a cognitive reference point has been a determinant force to help the successive American administrations frame decisions and undertake actions in the name of shielding threatened democracies (Noon, 2004, p. 352). To this end, pivotal historical events such as the World War I and II, the Cold War and the Vietnam War have been used to engender retrospection with the past and to influence public opinion. This rhetorical tactic of dwelling on the past to re-examine present situations is one of the strategies that has marked the political discourse of American presidents as well as celebrities. In fact, America's cultural icons, as trusted proxies, can also act in a way to sanction 


\section{Presidents' and Celebrities' Discourses}

ideologies and voice "systems of meaning production intimately related to practices of power, the power to define and defend reality" (Shepherd, 2006, p. 20). Thus, the political discourse of US presidents and celebrities, in regard to US strategic interests, is suited for the use of rhetorical devices such as analogies since they can "play a key role in the development of patterns of reasoning... with the express purpose of shaping the thinking patterns of the listener or reader" (Littlemore, 2015, p. 101). This analogical strategy charts safe routes for these politicians while leaning on common analogical arguments to interpreting the perplexed situations of the present.

\subsection{Research Objectives}

Being the case, this article attempts to achieve the following objectives:

1. To identify the common analogies used in the discourses of the four political actors.

2. To analyze the linguistic devices that reinforce the tenor of the analogical arguments.

3. To demystify the ideological significance of the analogical arguments stretching over many years as voiced by America's official political actors and cultural icons.

\section{LITERATURE REVIEW}

\subsection{CDA Input}

To meet its goals, this paper embarks on its analytical journey by adopting CDA as the study's main approach to examine the ways in which analogical arguments mobilized by these political actors can be constrained by common ideologies.

\subsection{Why Using Fairclough's CDA?}

One may wonder, however, why this research leans particularly on Fairclough's CDA to investigate the research objectives. In particular, this framework has the potential to make a contribution to reveal what ideological and hegemonic practices are embedded in the discourses. Identifying how US presidents' and celebrities' discourses produce power relations by focusing on language can raise "a critical consciousness" of the ideological power hiding in and behind such discourses (Fairclough, 2013, p. 3). One basic premise of Fairclough's CDA is that language use in discourse entails ideological meanings and that the investigation of the linguistic structure leads to extracting the ideological implication of any piece of discourse (Fairclough, 1993). To this end, by paying close attention to the linguistic realization of language in these political actors' discourses, this framework would bring acumen into the formation of common ideologies articulated through linguistic devices. For Fairclough, this level of analysis analyses the formal properties of the text and how these properties, dwelling on the linguistic features of the text, has the potential to reveal the extent to which linguistic toolkits in a text create certain power relations how these relations may legitimate, reproduce and challenge inequality (1993, p. 92). Accordingly, Fairclough's textual dimension is pertinent to this research as it aims to identify the ideologies hidden in presidents' and celebrities' through their linguistic choices. In this regard, linguistic features such as choices in vocabulary, grammar and rhetoric will be analyzed.

\subsection{CDA and ideology}

From critical discourse analysts' point of view, a specific thought is embodying ideological consideration. Norman Fairclough (2012, p. 5) maintains that CDA is critical as it calls attention to connections which may be hidden such as the amalgamation of language, power, and ideology. According to him, ideology encloses a pragmatic representation of the world offering cues to interpreting how discursive practice is engaged in more extensive social practice (ibid,. p. 30). As such, ideological power is identified as "the power to project one's practices as universal and "common sense"" where ideologies are understood as "meaning in 
the service of power" (Fairclough, 1993, p. 27). Based on this logic, discourse is depicted as an important vehicle to canvass unequal relations driven by ideological power embedded in language. This mirrors the unalterable link between the study of CDA and analogy since it is through the deconstruction of specific rhetorical toolkits that we come to fathom the ideological insinuations of the discourse. Being the case, an ideology moves from its simple consideration as a way of evincing values; to a way of excogitating, systematizing arguments, and deploying styles of persuasion (Rudyk, 2007, p. 69). In simpler terms, ideology is a concept that foreshadows people's socio-political representation of the world. This representational framework, in this study, is based on the ideological premises of analogy. It is, in fact, this interwoven relation between analogy and ideology that makes analogy a strong linguistic toolkit. Referring back to the focus of this paper, the politico-humanitarian discourses of US presidents and celebrities are aimed at persuading and to exercise a sort of rational argumentation through common analogical arguments. History has obviously justified the ways in which political and humanitarian discourses have been intertwined to reach ideological ends. Therefore, to undertake the analysis of a likely discourse, Schäffner (1996, p. 202) argues that "political speech analysis can be successful when it relates the details of linguistic behavior to political behavior". Therefore, CDA analysts accentuate the need for "interdisciplinary work in order to gain a proper understanding of how language functions in, for example, constituting and transmitting knowledge, in organizing social institutions or in exercising power" (Wodak and Meyer, 2001, p. 11). At this stage, comes the usefulness and practicality of incorporating analogy into the analytical study of the politico-humanitarian discourses of the selected political actors.

\subsection{Incorporating CDA and Analogy}

Analogy is a common feature in political speeches. This rhetorical device is used to draw comparison between contemporary situations and historical events or myths. Ideas, concepts or arguments are denoted to be interpreted in an analogy by comparing them with supposedly well-known phenomenon (Beard, 2000, p. 27). The study of historical analogies as suggested by Stanley Hoffmann stresses the idea that analogies have become an integral part of the American national style (Hoffmann, 1968). Conceptualized not only as fading away events, historical analogies drawing on history to cope with the blurry visions of the future function as a symbolic force of cultural memory (Noon, 2004). Thus, acting as a cognitive mechanism of persuasion, analogies are affecting general beliefs and shaping specific mental models representing opinions or emotions (Rudyk, 2007, p. 69). Moving from its inception as a simple linguistic device, an analogy is more of a logical argument. The structure of the argument paves the ground for a new understanding for the audience. The synergy between analogies as cognitive frames of reference and the choice of one over the other relies on the ideological mindset of the decision-makers (Houghton, 1996, p.549). This role is most crystal clear where an analogical argument is explicitly offered in backing up some ends. Many scholars have argued that policymakers are often biased in their thinking about the past (MacMillan, 2009). Like other manipulative rhetorical devices such as metaphor or metonymy, the use of analogy in political discourse is aimed to influence the audience, to exercise a kind of emotional containment and to generate consent for a particular political agenda (Taylor and Rourke, 1995). Based on this logic, analogical reasoning adopted by the four political actors seems to be deployed as a strategic political device through which these actors play up their common analogical arguments. By applying the theories of CDA and analogy, the paper aims at studying the ideological use of this rhetorical device to unveil the speakers' intentions. Through analogical lenses, the analysis of these political actors' discourses aims to map out common analogical grounds upon which their ideologies are grounded. Henceforth, the present paper adds to knowledge as how the congruity of historical analogies has repercussions of memory and intersubjectivity emanating from American presidents' and celebrities' discourses based on particular linguistic choices. 
The analysis of the analogies in the selected corpus draws on the three criteria offered by Inboden (2013), Brändström, Bynander and Hart (2004) and Kornprobst (2007) aimed at analyzing the speakers' strategic functions and putting under scrutiny ideological implications:

- The first criterion is derived from the "prescriptive power" of the analogous event that enables the decision-makers to extrapolate arguments and exercise actions that are fitting into the present situation. Since the desired goals were materialized in the past reinforces their claim that the same methods are expected to ring true in the actual situation (Inboden, 2013, p. 298).

- The second criterion is based on the analogy "proximity in time" which directs the decisionmakers to reckon that the dualistic relationship of past-present is doable regardless of time and space restrictions and that the analogy acts as a trusting guide for action (Brändström et al., p. 208).

- The third criterion is determined by the "generation effect" which refers to past events that have left their imprint engraved for generations and assembled a "repertoire of analogies" (Kornprobst, 2007, p. 40).

\subsection{Most Relevant Studies}

Throughout history, American leaders such as Roosevelt, Reagan, Clinton, and Bush have regularly reiterated historical analogies in justifying humanitarian policies where past lessons act as powerful tools to scramble with the complexity of the present and, thus, open an ideological avenue to interpret current events (Khong, 1992; Taylor and Rourke, 1995; Angstrom, 2011). Revisiting the history of using analogies in political communication, many researchers and analysts have conducted studies on the use of analogies in political discourses. Christopher Hemmer (2000, p. 14) who studies analogies in politics considers them as strategic rhetorical devices. He notes that "while policy makers are constrained by their beliefs, they are also capable of deliberately selecting a specific analogy based on explicit arguments". That's to say, analogies in political speeches are driven by political calculations.

Yuen Foong Khong's (1992) seminal study of the use of analogies by the Johnson Administration invoked both in public and private by the president and his advisors is a crucial step for assessing the power of these historical parallels to orient the decision-making process. Relying on interviews with senior officials, the author uses cognitive social psychology to support his argument about how leaders use analogies to perform specific informationprocessing tasks tied to political decision-making in Vietnam. Similarly, Hal Brands and Jeremi Suri (2016) offer interesting insights about the presence of "history in policy". They explore the dynamics behind the annexation of historical knowledge into US foreign policy through analogy. Their analytical study reviews analogy as "the beginning of inquiry into the continuities between past and present". According to them, "if a leader is warned that some foreign intervention will become 'another Vietnam' or 'another Iraq'... Such admonitions can provide useful frames of references... fleshing out the true dynamics of the challenge" (13).

Within the same line of reasoning, an interesting article written by Karine Prémont, Charles-Philippe David, and Vincent Boucher (2018) deals with the analogical construction of arguments to influence decision making in Iraq under Bush's administration. Through a systemic analysis, they find out that the decision-makers draw on a "width of competing analogies" from which Bush and his advisors chose to plan the post-invasion of Iraq. The conclusion to draw from the above studies is the fact that political discourse is historical in nature where analogy shapes its ideological tenor. In the case of the politico-humanitarian discourse under study, a remaining question needs to be tackled namely, to what extent is this highlighted conclusion applicable to map out common analogical grounds within American presidents' and celebrities' discourses. In fact, previous studies are valid but only give a picture of the use of historical analogies by America's official political actors. The ideological use of 
language, however, is not only restricted to American presidents, but, the power embedded in discourse can be uncovered in many other types of discourses such as celebrities' discourses.

This idea is ingrained by Foucault (1993, p. 334) who maintains that "power is not an institution, and not a structure; neither is it a certain strength we are endowed with; it is the name that one attributes to a complex strategical situation in a particular society". Celebrities, such as Ben Affleck and George Clooney, who have moved to mainstream politics, rely on past analogies to capitalize on the resurgence of US domestic security to obviate conflagration in Congo and Sudan. In addition, although these studies use different frameworks of discourse analysis, they have not incorporated CDA and analogy into their analysis. Embarking on such an investigation using the eclectic vein of CDA would offer a theoretical ground upon which I shall develop my analysis to examine how linguistic tools may reveal ideologies insinuated through analogical arguments.

\section{METHODOLOGY}

\subsection{Research Design and Method}

The research design is descriptive and analytical. It analyzes the four political actors' discourses in accordance with Fairclough's CDA and analogy theory. The current article makes use of a qualitative research method and is delimited to textual analysis which is concerned with the formal features of the texts, such as vocabulary, grammar and rhetoric. The analyzed textual features are namely:

- Ideologically contested words and concepts (Lexis): Lexical choices can be very revealing when referring to the event in topic. The analysis of lexicalization would target the interrelation between lexicalization and ideology to investigate how "vocabulary encodes ideology, systems of beliefs about the way the world is organized" (Fowler, 1991, p. 69).

- Verb tenses and processes (Grammar): The ideational function strongly rests on what Fairclough identifies as transitivity system. Transitivity can be described as the set of linguistic elements that realize our representation of the world in the clause (in particular grammar) through definite types of processes. Process is a very important feature, in that it constitutes the ideational or experiential centre of the clause (Halliday and Matthiessen, 2004, p. 170). The processes analyzed within the corpus are material and mental processes.

- Deixis (syntax): Pronouns can be considered as deictic expressions. Speakers have several strategies which enable them to manage the talk appropriately through the manipulation of the pronominal system. The study of person deixis can offer "a pronominal window into the thinking and attitude of" the actors towards "particular political topics and personalities" (Wilson, 1990, p. 59).

- Rhetorical figures (Rhetoric): are generally defined as "the faculty of observing in any given case, the available means of persuasion" (qtd in. Ross 6). Rhetoric tools are considered to be the most revealing, persuasive and expressive. The rhetorical figures analyzed in the research are metaphor, hyperbole, rhetorical question and parallelism.

\subsection{Corpus Selection}

The corpus analyzes excerpts of George W.H. Bush's, George H. Bush's, Ben Affleck's and George Clooney's speeches and interviews running in the period between 1989 and 2011. This considerable period of time is likely to cover US presidents' and celebrities' heated debates regarding dilemmas that mired the Third-World. This timeline is chosen as it encompasses important events such as the Gulf War, the Iraq War and US involvement in Congo and Darfur. My data are collected from the internet based on the official site of the American Presidency Project and the White House Government Archive where there is a record of all speeches of American presidents. The corpus also leans on celebrities' archive to extract speeches and interviews that are pertinent to the scope of the research. 
To activate its methodological scheme, the technique of analysis targets the use of lexis, grammar and rhetoric. The method applied to investigate the corpus leans on content analysis, a widely used method to study contents in discourse. It results in a tabulation of key words and sentences used by the speaker while evaluating the message and the linguistic style of presentation. Thus, this technique initiates a political contextualization followed by an analytical description of the most striking linguistic toolkits embraced by the speaker reinforced, in turn, by a textual interpretation to unearth the hidden meanings in the discourses. Through the analytical lenses of CDA and in accordance with the above mentioned criteria tied to analogy, the goal is to identify the thematic field from which analogies are derived and to scrutinize the linguistic tools used to convey it. The observed linguistic devices used in accordance with analogical arguments are: ideologically contested words and concepts (nouns, adjectives), tenses and processes (verb tenses, material and mental processes), deixis (pronouns: "we", "our" and "your") and rhetoric (parallelism, metaphor, and rhetorical question).

\section{FINDINGS}

The following analysis digs into how the emanation of past analogies from George $\mathrm{H}$. W. Bush, George .W Bush, Ben Affleck and Clooney diffuse individual or systemic perceptions, beliefs, and thought processes that are disclosed through discourse and maintained throughout time (Catalano and Waugh, 2013, p. 407). In the following extracts, the analysis brings to the fore how these politico-humanitarian discourses, although disjunctive in time, can be triggered by the speakers' predisposition to opt for common analogical arguments. Findings on analogical analysis in political communication are to be tested to bring into light results specific to the presidents' and celebrities' contexts.

\subsection{Retreat Strategy Analogy}

In their discourses, George H.W. Bush, George W. Bush, Ben Affleck and Clooney resort to analogy to draw on socially shared opinions about the repercussions of the retreat strategy in the Third-World. In fact, these shared opinions entail "common sense reasoning schemes" for the sake of persuasion (van Dijk, 2006, p. 98). Put differently, they employ the analogy of retreat strategy to inform audiences about the urgency of implementing decisions and, thus, "to mobilize public support for decisions made or about to be made" (Record, 1993, p.3). The following analysis maps out the speakers' common analogical arguments while targeting their linguistic choices.

\subsubsection{Bush H.W.'s Analogical Argument}

President George H.W. Bush's early references to Vietnam War as tied to the retreat strategy analogy demonstrate the resonance of that theme in American memory and provide fertile rhetorical ground. Indeed, even before 9/11 the American rhetoric begins with an emotional containment based on analogical reasoning to appeal to the American audience and to win their consent. In his 1989 Inaugural Address as the 41st US President he stated:

And our great parties have too often been far apart and untrusting of each other. It's been this way since Vietnam. That war cleaves us still. $\underline{\text { But}}$, friends, that war began in earnest a quarter of a century ago, and surely the statute of limitation has been reached. This is a fact: The final lesson of Vietnam is that no great nation can long afford to be sundered by a memory (Inaugural Address, 1989). 
The excerpt begins with an appeal to the pathos of Americans through the use of the ideologically contested words "far apart", "untrusting" and "cleaves". By leaning on these negative adjectives and verbs, Bush recalls the repercussions of the retreat strategy in Vietnam by triggering its legacies in Americans' memory. This lexical choice aims to emphasize already acknowledged facts and to summon the alleged memory of the retreat strategy which exhibits the culture of trauma and failure policies (Lewin, 1993). Through this lexical choice, Bush seems to construct the Gulf issue as a national security issue for Americans while appealing to their fears of insecurity and failure by raising the phantom of Vietnam-retreat strategy.

However, exploring his grammatical choices, Bush seems to draw a fine line separating the past with its heavy legacies and mistakes from the present upcoming. In fact, he presents a rhetorical transcendence of the present dilemma while leaning on the Vietnam War lesson. The transcendence he offers is, thus, constrained by the retreat analogy. The temporal oscillation from present progressive, to simple past to simple present is disrupted by the coordinating conjunction " $b u t$ ". This temporal structure places contrasted perspectives where opposites are more knowable when put besides each other to help the audience differentiating old facts from present facts (Kazemian and Hashemi, 2017). Therefore, the content after the contrasting sentences is the emphasized idea.

Using this antithesis, the transcendence of current crises of being "far apart and untrusting of each other" works to naturalize the dilemmas of the present by rhetorically situating them in the past. The tense begins in the present perfect "it's been this way", moves to the past "that war began" and then resolves with purposeful sentences to the present "limitation has been reached. This is a fact: The final lesson of Vietnam is ..." This temporal move is intended to acknowledge the past as the very source behind the present's resolutions. Yet, this rhetorical structure bears on ideological assumption to move from the past's repercussions into the consolidation of the present as a safe conduit to maintain national unity.

In fact, this claim is, further, justified through Bush's reliance on the metaphorical evocation "The final lesson of Vietnam is that no great nation can long afford to be sundered by a memory". This along the retreat strategy analogy involves tactile reconstructions of history and what kinds of lessons history can actually offer to the US to face the present. The subtle argument that the negative adjective "sundered" anticipates is how US history in Vietnam should become a source of perspective and power to address challenges and to preserve the status of a great nation. It is contributing to the logos of Bush's argument by drawing a comparison between the past and the present to foreground that the retreat strategy should be nothing but a "shortcut to rationality" (Jervis, 1976, p. 220). By dwelling on the factual and final lesson of Vietnam along this temporal structure, Bush intends to approach the retreat strategy in Vietnam as fear tactics to play on the whims of Americans where the imprints of past failure should chart safe routes for US unforeseen overseas commitments in the Gulf region.

Following the same logic, in his 1991 Address to US Armed Forces in the Persian Gulf region, he evokes the retreat strategy stating that:

Americans today are confident of our country, confident of our future, and most of all, confident about you. We promised you'd be given the means to fight. We promised not to look over your shoulder. We promised this would not be another Vietnam. And we kept that promise. The specter of Vietnam has been buried forever in the desert sands of the Arabian Peninsula (Radio Address, 1991).

Exploring lexical choices, in this excerpt Bush appeals to the logos of his analogical argument by dwelling on US key consolidated tenets. The lexical choice of the adjective "confident" and its collocation with the key words "our country", "our future", and "you" speak 
to this claim. By maintaining the present's tenets, Bush aims to foreground that the immunity of the US lies in its pulling away from the past failure prescribed by the retreat strategy in Vietnam. The fitness of collocation may reveal a rationale behind the selection of these lexical items within the excerpt. In addition, his grammatical choices fall within the same line of reasoning. To advance his claim, Bush leans on the deictic system. His use of the collective personal pronoun "we" embedded in the parallel structure "We promised you'd be given the means to fight. We promised not to look over your shoulder. We promised this would not be another Vietnam" enhances a sense of cohesivization and constitutes a call to manufacture an opportunity to avoid the perilous foreign policy choices linked to the retreat strategy. At this stage, he calls back to mind the Vietnam War to chain the agency of Americans and armed forces to go beyond the broken promises and to avoid creating "another Vietnam".

The tense shifting and syntax in this extract also works in tandem with Bush's threetemporal structure. In fact, the temporal structure of his discourse oscillates between simple present, simple past and present perfect as he connects the Vietnam memory with arguments about how the US should approach present. His first sentence begins in the simple present to foreground his assumptions and creeds about the present. Bush strategically uses the collective pronoun "our" like in "our country", "our future" to reinforce this perspective about the present with a sense of unification. This unification is, however, subject to the temptations of the past. Bush recalls back the Vietnam memory through his use of the simple past to make it as the buried ghost that should never come back to taint Americans confidence or demolish their tenets. The final sentence ends in the present perfect where Bush links the maintenance of such confidence and the realization of America's promise to the fact that "the specter of Vietnam has been buried forever in the desert sands of the Arabian Peninsula". His temporal transition offers a transcendence of the past and, thus, casts a move from Vietnam memory into the present's resolutions as a channel to dauntless victories in the Gulf region. His metaphorical evocation of the "specter of Vietnam" reinforced by the present perfect tense, foregrounds his analogical reasoning that the retreat strategy is no longer revivable. Accentuated through this temporal structure, the retreat strategy emanating from the Vietnam memory falls within the "generation effect" criteria (Kornprobst, 2007). As Michel Foucault (1993, p. 66) argues, all reconfigurations of memory have history recasting the interwoven relationship between memory and history where "history is an operation of power, an intensifier of power which is inseparable from political experiences, agencies and their legitimacy".

\subsubsection{Bush W.'s Analogical Argument}

The same pretext was elaborated on during the Iraq War to frame the retreat strategy as a challenge to US interests in Iraq. In fact, George W. Bush (2010, p. 367) draws on the Vietnam memory along the retreat strategy to maintain that:

If Iraq split along sectarian lines, our mission would be doomed. We could be looking at a repeat of Vietnam--a humiliating loss for the country, a shattering blow to the military, and a dramatic setback for our interests... If anything, the consequences of defeat in Iraq would be even worse than in Vietnam. We would leave al Qaeda with a safe haven in a country with vast oil reserves. We would embolden a hostile Iran in its pursuit of nuclear weapons (Decision Point, 2010)

In this excerpt, Bush's lexical choice speaks to the ways his ideologically contested words are aimed to "generate an ideologically charged meaning" (Spurr, 2012, p.62). The hypothetical possibility aroused by Bush "if Iraq split along sectarian lines" is aimed to anticipate the same perils emanating out of US retreat in Vietnam. His hypothesis is directly followed by a three part list " $a$ humiliating loss for the country, a shattering blow to the 
military, and a dramatic setback of our interest" embedding a series of negative adjectives "humiliating", "shattering", and "dramatic". This lexical choice based on US moral, military and economic failures aims to awaken Americans' memory to the repercussions entailed by the retreat strategy affecting US "country", "military", and "interests". Bush's lexical choice is linguistically crystallized via the aforementioned collocations to contextualize his analogical argument around "a repeat Vietnam".

To accredit the dialogical tenor of his argument, the latter goes on to engage his audience into a bipartite temporal structure of the past moving and possibly affecting the present. At this stage, he has recourse to material verbal processes with negative connotations "we would leave" and "we would embolden". Along these material processes, he underlines through negative appraisement the two social actors "Al Qaeda" and "Iran" deemed respectively as profiteer and hostile weaponeer. This choice in lexis in conjunction with the aforementioned negative processes seems contributing to the logos of the argument by drawing a direct comparison between the retreat strategy in Vietnam and the importance of intervention in Iraq. Using negative material processes along the inclusive personal pronoun "we", Bush intends to foresee future threats eating away at Americans' strategic interests in the region which contradicts his insistence on a justice-based approach in Iraq. As Isabella Fairclough and Norman Fairclough note, in some instances political argumentation is more about the exercise of power than achieving particular objective policy that the argumentation is purportedly about (2012, p. 114).

To empower his claim, these negative processes are preceded by a hyperbole to exaggerate that "... If anything, the consequences of defeat in Iraq would be even worse than in Vietnam". This hyperbolic construction of the retreat strategy and its rebound is ideologically linked to the logos of the argument where Bush intentionally builds similarities between past and present and insinuates past failures to approach the present with suspicion. Hence, he makes appeal to the logos of his audience trying to convince them that Vietnam's failure is as important as that in Iraq to awaken their memories of fear and loss. At this stage, the analogy makes an annexation into US interests that are inextricably linked to stability in key regions such as Iraq. Bearing in mind that the feared outcomes were materialized in the analogous past case reinforces Bush's claim that the same methods are expected to ring true in the actual situation (Inboden, 2013).

\subsubsection{Ben Affleck's Analogical Argument}

Interestingly to note, the power of past analogies as contagious discursive practices also affects the discourse of American celebrities. The phenomenon of the celebrity-politician can be seen to declare the launching of a political order where celebrities' role in boosting the progress of global citizenship, is becoming noteworthy (Bennett, 1998, p. 146). Based on the same arguments, Ben Affleck before the US Committee on Foreign Relations Senate has recourse to Afghanistan and Iraq analogies to stress the importance of intervention in Congo. His linguistic choices are analyzed in tandem with his analogical argument. He argues that:

You know, there's a lot of rancor and anger around elections in what we like to think of as stable democracies like our own. So imagine what it's like, you know, in a nascent democracy that's still recovering from ongoing humanitarian conflict, atrocities, political crises. You know, DRC is the eighth-poorest country in the world; it is the fifth on the Failed States Index - worse than Afghanistan and Iraq and Haiti. And failure here really, genuinely, honestly could be catastrophic, you know? (CSIS November 30, 2010)

Within the same line of Bush's reasoning, Ben Affleck's vocabulary, touching on the recognition of the Congo genocide as an upcoming failed catastrophic experience, is 


\section{Presidents' and Celebrities' Discourses}

symbolically loaded and highly contested based on the degree to which the word "failure" is interchangeable with the retreat strategy. As Fairclough points out, "the meanings of words and the wording of meanings are matters which are socially variable and socially contested", imbued with ideological significance (1993, p. 185). His lexical choice of the ideologically contested words "failure" and "catastrophic" seems to resort to cognitive mechanisms of persuasion where these two words have the power to trigger Americans' memories and heat up fear appeals about the legacies of retreat strategies in key regions (Rudyk, 2007, p. 69).

To back up his lexical choices, he draws on the second personal pronoun "you" along the mental cognitive process "know". Ben Affleck links the avoidance of such catastrophic failures to the "cognitive and rational manner" that are acquired by US policymakers to understand and to contain likely situations (van Leeuwen, 2008, p. 58). Indeed, having a close look at the first three sentences, the personal pronoun "you" is represented as a sensor of cognitive mental processes where Ben Affleck portrays this social actor as rational enough to excogitate about the evils of "nascent democracy that's still recovering from ongoing humanitarian conflict, atrocities, and political crises". Thus, he excogitates that past lessons in Iraq, Afghanistan and Haiti should act as a yardstick against which rational decisions in Congo have to be enacted. Using mental processes is, thus, aimed to offer cognitive orientation to deplete the dangers surrounding Congo while drawing on the retreat strategy repercussions.

He goes on to connect previous arguments through the tactical use of the rhetorical question "failure here really, genuinely, honestly could be catastrophic, you know?". He cognitively triggers his audience's memory as he analogizes the retreat strategy in Afghanistan, Iraq and Haiti to the present situation in Congo. The latter asserts that inaction is always dangerous and nefarious. This rhetorical question touches on the illocutionary force of "warning" in an attempt to get the hearer to undertake actions (Searle, 1979). Accordingly, the grammatical mood of the sentence triggers an imperative mode where Ben Affleck asserts that actions should be undertaken as the Congo genocide would interrogate American commitments. In his testimony before the American Senate Foreign Relations Committee, he argues:

"My testimony today is, in short, a plea to you to insist that the Executive Branch takes the necessary steps to implement the key provisions of the 2006 law. I strongly believe that if we continue to place the Congo on the back burner of US policy it will come back to haunt us" (Congress Testimony, 2011).

His lexical choice of the verb "haunt" seems to draw a subtle analogy to previous hazards coming out of the retreat strategy. This lexical choice of the verb is directed towards moving emotions in his audience by appealing to their pathos and presenting the retreat strategy as a haunting ghost. In fact, this verb has political resonance in American statecraft discourse as it denotes the haunting nature of the ghosts of state terror (Jackson, 2008). Here, the analogical argument is also emphasized through the metaphorical expression "if we continue to place the Congo on the back burner of US policy it will come back to haunt us". The ghost metaphor, conditioned by the analogy, is mobilized to accentuate the ideological tenor of Ben Affleck's analogical argument where past retreat strategies in key regions are nefarious for US interests.

To advance his argument, Ben Affleck's verbal choices lean on the material processes "take" and "implement" to underscore the avoidance of previous failures to the decisive action of the Executive Branch and the American government. Drawing on the collective personal pronoun "we" to weave collective identity and responsibility (Bramley 2001:263), he explicitly warns that transnational problems of previous failures are targeting all Americans. Based on these accounts, the analogy is contributing to the logos of Ben Affleck's argument by 
juxtaposing the threatening outcomes of the retreat strategy with the hazards that could follow to menace US interests in a peaceful Congo.

By linking his discourse on Congo to "past experiences" in Afghanistan and Iraq, Ben Affleck's analogy is based on what Fairclough (1993, p. 65) terms coherence, which is how discourse fits in with our previous understanding of the world. This analogy is, accordingly, based on the "proximity in time" criterion as its memories are still vivid and recent. By calling to mind this connection, Ben Affleck excogitates that this entails at its core the application of the cause-effect relationship to rationalize future decisions where the analogy serves as a guiding roadmap for US actions in Congo (Brändström et al., 2004, p. 208).

\subsubsection{Clooney's Analogical Argument}

In his 2006 Address to the UN as an American activist involved in Darfur, Clooney chains the imaginary of a catastrophic Sudan through the analogy of the Holocaust and the repercussion of the retreat strategy. He states that:

In many ways, it's unfair, but it is, nevertheless, true that this genocide will be on your watch. How you deal with it will be your legacy, your Rwanda, your Auschwitz. We were brought up to believe that the U.N. was formed to ensure that the Holocaust could never happen again. We believe in you so strongly. We need you so badly. We've come so far. We're -We're -- We're one "yes" away from ending this. And, if not the U.N., then who? (UN Security Council, September 14, 2006).

In this excerpt, Clooney's vocabulary, touching on the recognition of the Holocaust as a revived experience, is symbolically loaded and highly contested based on the degree to which the word 'genocide' is interchangeable with the word 'Holocaust'. The latter makes use of the ideologically contested concepts "genocide", "Holocaust" and "legacy". His linguistic resources seem to resort to cognitive mechanisms of persuasion where these concepts have the power to trigger Western memory and heat up fear appeals about failures to contain past traumatic events (Rudyk, 2007, p. 69). As it is argued by Fairclough (2001), the selection of particular pronouns in discourse is never arbitrary as the use or the over-emphasis of certain pronouns is strategic to create the desired effect and serve the communicative event. Grammatically, the collocation of the pronoun "your" with the key words "legacy," "Rwanda" and "Auschwitz" is used to convey generally admitted truth while questioning the responsibility of the UN.

Using this pronominal system, Clooney foregrounds the geopolitical legacies while emphasizing the haunting nature of ill-contained traumatic events that end up plaguing the credibility of Western institutions such as the UN and its American allies. At this stage, Clooney's analogical reasoning based on the geographical repercussions of the retreat strategy, longs to impose familiarity on present issues in Sudan where the analogy exhibits the culture of terror with its generational trauma (Lewin, 1993). To reinforce his argument, he has recourse to parallel structures as a persuasive strategy to convince audiences that American-Western lack of fulfillment in Darfur is reiterating what have been experienced in the past. As dealing with it will be "your legacy, your Rwanda, your Auschwitz", Clooney is quick to analogize the current events in Darfur with failures in Rwanda and Auschwitz. The retreat strategy with its failed policies is, thus, called upon to spur the UN to fight the same evil that has spurred generations and "to ensure that the Holocaust could never happen again".

In his CNN Interview with Larry King, Clooney articulates the same arguments regarding actions that involve tactile reconstructions of history to stop Sudan Genocide. He states: 
What's important now is we know what happens when we don't act

We didn't act fast enough in the Congo. We didn't act fast enough in Darfur. We didn't act fast enough in Rwanda. We know what happens when we don't. And it costs us billions. (CNN Interview, 2010).

The rhetorical action of this excerpt is orchestrated on a bipartite structure where the temporal markers of the present "we know what happens when we don't' act" and the past "we didn't act fast" interpenetrate. The past, embodied in the memory of the retreat strategy in Rwanda, is more than a distant event. Through the use of the mental process "know" along the inclusive personal pronoun "We", Clooney links the avoidance of the past to Americans' acquired knowledge and experience. He explicitly draws analogy between Darfur and Rwanda through the parallel verbal structure "we didn't act fast enough" to put the emphasis on the geopolitical repercussions of a likely retreat strategy in Sudan. At this stage, the collocation of the collective pronoun "we" with its inclusive connotations refereeing to the American government and Americans, with negative material verbs "didn't act fast" is aimed to foreground the common responsibility and to emphasize the haunting nature of ill-contained traumatic events that end up threatening US interests. This technique of using negative material verbs along the personal pronoun "we" is "highly pervasive" and "replicating a sense of emotional, intellectual or sensory pressure in the audience" (R. Cockcroft and S. Cockcroft, 2014, p. 231). Accordingly, Clooney creates cohesivization and appeals to Americans' logos longing for victory and achievement. Positing the analogy as a moment of failure, he puts Americans in a defensive frame of mind to acknowledge the importance of interventionism in Sudan for "our" benefits as "it costs us billions". Logos, here, is insinuated through these linguistic devices to create a cognitive resonance within his audience where his analogy anchors the "proximity in time" criteria (Brändström et al., 2004, p. 208).

\section{DISCUSSION}

It can be opined that the use of such linguistic devices along the analogical arguments is indicative of context and mind control because George H. W. Bush, George .W Bush, Ben Affleck and Clooney appear to have taken advantage of the situation (war, violence, threat posed not only to the Third-World but to American interests), participants (Western/American audience) and mental representations (knowledge and beliefs) to build their arguments. In the analyzed extracts, the common arguments drawing on the retreat strategy, at ostensibly different historical moments and contexts, show the role of analogies to stand within these discourses as discursive ideological representations. Their materialization through specific linguistic devices and their articulation by presidents as well as celebrities brings to mind how America's political actors, although disjunctive in time and status, "invariably will continue to be influenced by past events and what they believe those events teach" (Record, 1998, p. 23). In fact, analogical arguments drawn from the theme of retreat strategy have a deep influence on the American people. This is because the thematic source domain from which these actors derive their analogical reasoning is deeply rooted in American political culture. This reasoning creates an ideological assertion on broader politics of American preemptive security tied to its precautionary action where preventive security leans on "imagined catastrophic futures" through which protective policies are vindicated (Marieke De Goede, 2008, p.162). The explicit link between the analogical arguments and the linguistic devices used anticipates a kind of discursive logic for the sake of persuasion.

\section{CONCLUSION}


Though disjunctive in time and context, Bush .W.H's, Bush. H's, Ben Affleck's and Clooney's common analogical reasoning which echoes the repercussions of the retreat strategy is epitomized in the linguistic devices they resort to in order to reinforce the ideological tenor of their arguments. The interwoven relation between the analogy and the linguistic choices reflects Roxanne Doty's (2007, p. 7) argument that the understanding of these discursive meanings to be "fixed and true" is evidence of the link between power and knowledge. The research results do also support CDA social view of language. That is to say, language for critical discourse analysts is not simply a mean of communication, but it is a social practice ideologically shaped by relations of power and struggles over power. Because of the limited scope of this paper, future research can embark on a deeper investigation by broadening the scope of the corpus.

\section{References}

Beard, A. (2015). The language of politics. New York: Routledge.

Bennett, T. (1998). Culture: A reformer's Science. London: Sage Publications.

Brändström, A., Bynander, F., and Hart, A. (2004), 'Governing by Looking Back: Historical Analogies and Crisis Management', Public Administration, 82, pp. 191-210. (2017). Emergency Policy, 39-58. doi:10.4324/9781315256641-10

Bush, G H.W. (1989, January 20). The Inaugural Address. https://www.presidency.ucsb.edu/documents/inaugural-address

--- (1991) Radio Address to United States Armed Forces Stationed in the Persian Gulf Region. Retrieved from https://www. Radio Address to United States Armed Forces Stationed in the Persian Gulf Region | The American Presidency Project (ucsb.edu)

Bush, G. W. (2010). Decision points. New York: Crown.

Catalano, T., \& Waugh, L. R. (2013). The Ideologies Behind Newspaper Crime Reports of Latinos and Wall Street/CEOs: A Critical Analysis of Metonymy in Text and Image. Critical Discourse Studies, 10(4), 406-426. doi:10.1080/17405904.2013.813774

Center for Strategic and International Studies (CSIS). (2010, November). U.S. Foreign Policy in the Democratic Republic of Congo. Washington, D.C. https://csis-websiteprod.s3.amazonaws.com/s3fs-public/event/101201_csis-drc_policy.pdf.

Clooney, G. (2006, September 14). 'United Nations Security Council Address on Darfur. Retrieved from https://www. American Rhetoric: George Clooney - Address to the United Nations Security Council on Darfur.

---. (2010, October 14). Interview With George Clooney. Interview by Larry King. CNN Larry King Live. Atlanta, Georgia: http://edition.cnn.com/TRANSCRIPTS/1010/14/lk1.01.html.

Cockcroft, R., \& Cockcroft, S. (2014). Persuading people: An introduction to rhetoric (3rd ed.). London: Palgrave.

De Goede, M. (2008). The Politics of Preemption and the War on Terror in Europe. European Journal of International Relations, 14(1), 161-185. doi:10.1177/1354066107087764

Deubel, T. H,. Brands,. H, and Suri, J. (2018). The Power of the Past: History and Statecraft. Das Historisch-Politische Buch, 66(1), 11-12. doi:10.3790/hpb.66.1.11

Fairclough, I., \& Fairclough, N. (2012). Political discourse analysis: A method for advanced students. London: Routledge.

Fairclough, N. (1993). Discourse and Social Change. Cambridge: Polity Press.

Fairclough, N. (2013). Language and Power (2nd ed.). London and New York: Routledge.

Foucault, M. (1993). Society Must be Defended. London: Penguin Books.

Fowler, R. (1991). Language in the News: Discourse and Ideology in the Press. London: Routledge.

Hague, R., Harrop, M., \& McCormick, J. (2016). Comparative Government and Politics, 90107. doi:10.1007/978-1-137-52838-4_6 
Halliday, M., \& Matthiessen, C. M. (2004). Halliday's Introduction to Functional Grammar. London: Routledge.

Hemmer, C. (2012). Which Lessons Matter?: American Foreign Policy Decision Making in the Middle East, 1979-1987. SUNY Press.

Houghton, D. P. (1996). The Role of Analogical Reasoning in Novel Foreign-Policy Situations. British Journal of Political Science, 26(4), 523-552. doi:10.1017/s0007123400007596

Inboden, W. (2013). Statecraft, Decision-Making, and the Varieties of Historical Experience: A Taxonomy. Journal of Strategic Studies, 37(2), 291-318. doi:10.1080/01402390.2013.829402

Jackson, R. (2008). The ghosts of state terror: Knowledge, Politics and Terrorism studies. Critical Studies on Terrorism, 1(3), 377-392. doi:10.1080/17539150802515046

Jervis, R. (1976). Perception and Misperception in International Politics. UK: Princeton University Press.

Kazemian, B., \& Hashemi, S. (2017). A Radical Shift to a Profound and Rigorous Investigation in Political Discourse: An Integrated Approach. International Journal of English Linguistics, 7(3), 115. doi:10.5539/ijel.v7n3p115

Khong, Y. F. (1992). Analogies at War: Korea, Munich, Dien Bien Phu, and the Vietnam Decisions of 1965. New Jersey: Princeton University Press.

Kornprobst, M. (2007). Millennium: Journal of International Studies, 36(1), 29-49. doi:10.1177/03058298070360010301

Leeuwen, T. V. (2008). Discourse and Practice: New Tools for Critical Discourse Analysis. New York: Oxford University Press.

Lewin, C. M. (1993). Negotiated Selves in the Holocaust. Ethos, 21(3), 295-318. doi:10.1525/eth.1993.21.3.02a00030

Littlemore, J. (2015). Metonymy. Cambridge: Cambridge University Press.

MacMillan, M. (2010). Dangerous Games: The Uses and Abuses of History. New York: Modern Library.

Noon, D. H. (2004). Operation Enduring Analogy: World War II, the War on Terror, and the Uses of Historical Memory. Rhetoric \& Public Affairs, 7(3), 339-364. doi:10.1353/rap.2005.0015

Parry-Giles, S. J., \& Parry-Giles, T. (2000). Collective memory, political nostalgia, and the rhetorical presidency: Bill Clinton's commemoration of the march on Washington, August 28, 1998. Quarterly Journal of Speech,86(4), 417-437. doi:10.1080/00335630009384308

Prémont, K., David, C., \& Boucher, V. (2018). Diplomacy \& Statecraft, 29(2), 298-327. doi:10.1080/09592296.2018.1453983

Record, J. (1998). Perils of Reasoning by Historical Analogy: Munich, Vietnam, and American Use of Force Since 1945. US: BiblioGov.

Searle, J. R., \& Searle, J. R. (1969). Speech Acts: An Essay in the Philosophy of Language. UK: Cambridge University Press.

Rudyk. I. (2007). "Power Relations in President Bush's State of the Union Speech". International Journal of Language Society and Culture, 5 (23) ,68-76.

Schäffner, C. (1996). Editorial: Political speeches and discourse analysis. Current Issues in Language and Society, 3(3), 201-204

United States. Congress, United States House of Representatives, \& Committee on Foreign Affairs. (2011). The Democratic Republic of the Congo: Securing Peace in the Midst of Tragedy. Retrieved from https://www.govinfo.gov/content/pkg/CHRG112hhrg65058/html/CHRG-112hhrg65058.htm 
van Dijk, T. A. (2006). Ideology and Discourse. Oxford Handbooks Online. doi:10.1093/oxford/9780199585977.013.007

Wilson, J. (1990). Politically Speaking: The Pragmatic Analysis of Political Language. UK: Wiley-Blackwell.

Wodak, R., \& Meyer, M. (2009). Methods for Critical Discourse Analysis. London: Sage Publication.

\section{AUTHOR'S BIO}

Hana Riani holds a PhD in American Culture Studies. My study foci are primarily: NeoImperialism, Soft Power Politics, Gender and Celebrity Studies, and Political Discourse. My research interests and academic fields are also rooted in Critical Discourse Analysis especially modern rhetoric. I teach American Culture, History and Politics. I participated in several international conferences pertaining to my research interests. 